\title{
Coroless, effective ingredient isolated from traditional Chinese medicine for the prevention and treatment of Covid-19
}

\author{
Nie Leng ${ }^{1,2^{*}}$ Liang Youdong ${ }^{3}$, Yang Xinwei ${ }^{1}$ \\ 1. Suzhou Primreg Gene Company, Suzhou, China, 215128 \\ 2. Shenzhen Baiyue Gene Company, Shenzhen, China, 518110; \\ 3. Beijing Century Healthcare Co.,Ltd. Beijing, China, 100085 \\ Corresponding author: nieleng@hotmail.com
}

Abstract:

We believe that a good medicine for the prevention and treatment of Covid-19 requires three points: 1 . Effectively inhibit the cells from being infected by Covid-19; 2. Quickly repair lung damage; 3. Non-toxic and harmless. Fortunately, from the treasure depot of Chinese traditional medicine, we found Kyllinga brevifolia Rottb, which is sufficient for three points and can be used for prevention, treatment and rehabilitation. Not only that, we have isolated the active ingredient of the Kyllinga brevifolia Rottb, named it Coroless, and verified that Coroless inhibits the Covid-19 from infecting cells through in vitro cell experiments. 


\section{Introduction}

As of January 31, 2021, more than 100 million patients have been diagnosed with Covid-19 infections globally and more than 2 million people have died. The new corona virus has damages to the lung, kidney, liver, and cardiovascular system ${ }^{[1]}$. There is an urgent need for Covid-19 prevention, treatment and rehabilitation drugs. We believe that a good medicine for the prevention and treatment of new corona virus requires three points: 1. Effectively inhibit the cells from being infected by Covid19; 2. Quickly repair lung damage; 3. Non-toxic. Fortunately, from the treasure depot of Chinese traditional medicine, we found the Kyllinga brevifolia Rottb, which is sufficient for three points and can be used for prevention, treatment and rehabilitation ${ }^{[2-3]}$.

Kyllinga brevifolia Rottb can cure flu, colds, headaches, muscle pain, coughs, malaria, jaundice, dysentery, sores, swelling, and bruises [4]. Coincidentally, the cluster-shaped seed ball of the herb ${ }^{[5]}$ is similar to the Covid-19 (see Figure 1).
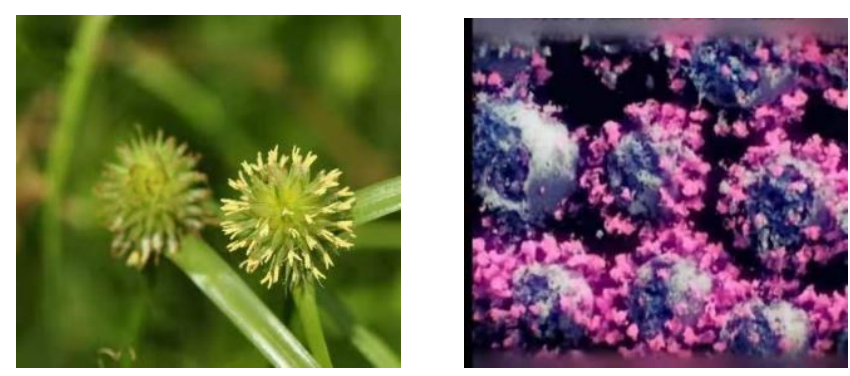

Figure 1 kyllinga seed balls and Cryo-electron micrographs of covid-19 virus

Kyllinga is distributed in East Asia, Southeast Asia, South Asia, West Africa, Central Africa, South Africa, North America, South America, and Oceania. Kyllinga is non-toxic and harmless, and it is food for cattle, sheep and fish in Central South China. For developing countries in Asia, Africa 
and Latin America, for Covid-19 prevention and treatment, Kyllinga is an available emergency option. However, the origins of medicinal materials are different, thus the efficacy of this very medicine varies greatly. Fortunately, we isolated the active ingredient from the volatile oil of the herb and named it Coroless. Cell experiments confirmed that it effectively inhibits_Covid-19 infection.

\section{Material and methods}

Covid-19 pseudo-virus cell infection experiment. Coroless $(5 \mu \mathrm{L} / \mathrm{mL})$ is diluted serially. After the drug is diluted, and prepare the Covid-19 pseudo-virus (Beijing Sino Biological Inc.). Each take $50 \mu \mathrm{L}$ and mix in equal volume, incubate at $37^{\circ} \mathrm{C}$ for $1 \mathrm{~h}$, and add to the 293T-ACE2 cells plated in advance, with 2 replicate wells for each dosage. After culturing for $24 \mathrm{~h}, 48 \mathrm{~h}$, and $72 \mathrm{~h}$, the cell status was observed and photographed, and the Luciferase luminescence value of the samples in the 96-well plate was detected with a chemiluminescence instrument. The positive control is Covid-19 pseudo-virus infection experiment. The negative control is a normal cell growth experiment. To evaluate the effect of Coroless on cell growth, $50 \mu \mathrm{L}$ of Coroless was diluted and added to the pre-plated 293TACE2 cells in 2 replicated wells; the cells were cultured for $24 \mathrm{~h}, 48 \mathrm{~h}$, and $72 \mathrm{~h}$, and then the cell status was observed and photographed. The experimental process of Covid-19 pseudo-virus cell with Kyllinga is the same as that of Coroless.

ACE2: RBD molecule binding competition inhibition experiment. Coroless $(5 \mu \mathrm{L} / \mathrm{mL})$ and Kyllinga are serially diluted. The inhibitor screening kit used was produced and prepared by Beijing Sino Biological Inc.(item number: KIT001, batch number: CW14MY1401). The 
experiment process was carried out according to the kit instructions.

\section{Results and discussion}

In order to verify the cytotoxicity, Coroless was incubated with the cells for 72 hours. Figure 2 shows that the cells almost cover the culture plate, indicating that Coroless has no harm to cell growth. We have also observed that after the pseudo-virus is incubated with the cells, a large number of cells die. However, with the pseudo-virus and Coroless both incubated with the cells, the cells proliferate well.

Our previous work has shown that Kyllinga is effective in preventing, treating and recovering pneumonia caused by Covid-19 [2,3]. After the Coroless in Kyllinga was isolated, the in vitro cell efficacy was tested. Surprisingly, as shown in Table 1, Coroless's inhibition rate against_Covid19 pseudo-virus infection is as high as $98.89 \%$, and the inhibition rate against Covid-19 pseudo-virus infection is still over 50\% after 128 -fold dilution. As shown in Table 2, the inhibition rate of Kyllinga against the Covid-19 pseudo-virus is as high as $87.71 \%$. It shows that Coroless, like Kyllinga, effectively inhibits_Covid-19 pseudo-virus infecting cells.

In the high-concentration Covid-19 experiment, Kyllinga effectively inhibited the cell death caused by the new corona virus, and the halfinhibitory concentration $\mathrm{IC}_{50}$ was $3.76 \mathrm{mg} / \mathrm{mL}$, which was equivalent to the actual clinical Kyllinga concentration ${ }^{[2,3]}$. The Coroless against Covid19 experiment is being verified, and the preliminary experiments are also gratifying. Coroless also inhibits the infection of cells with high concentrations of the new corona virus. The research is still in progress.

In order to explore the mechanism of Coroless and Kyllinga inhibiting the new coronavirus infection, we have done Coroless and Kyllinga ACE2: 
RBD competitive inhibition experiment. The results of Table 4 and Figure 3 show that the Kyllinga has a competitive inhibitory effect on the binding of ACE2:RBD. ACE2 is the cell indicating receptor of Covid-19, RBD is the receptor binding area of the new corona virus spike protein, and the ELIS experiment shows that the inhibition rate is $69 \%$. However, Coroless has almost no effect on the binding competition inhibition of ACE2:RBD, as shown in Table 3. It shows that one possible way for the herb to inhibit Covid-19 infection is to interfere with the binding of spike protein to the ACE2 receptor, and Coroless does not function in this way. Although there are differences, the mechanism of Coroless and Kyllinga inhibiting the new corona virus infection should be related to GTP enzyme ${ }^{[6]}$.

\section{Conclusions and suggestions}

We have confirmed through cell infection experiments that Coroless and Kyllinga can inhibit the infection of cells by Covid-19. In order to verify the safety of Coroless and the efficacy of damage repair, Dr. Nie self-administered Coroless ( $7 \mathrm{mg}$ per day for three days) to treat oral ulcers, which has significant effects and no adverse reactions. The preliminary results of Coroless in clinic for Covid-19 are also encouraging. The new corona virus pandemic is severe. Especially in developing countries where medical resources are scarce,_Kyllinga is one choice for persons in need. People in one world do things in one world. We hope that research institutions, pharmacies and hospitals in the world will cooperate with us to advance the follow-up research of Coroless, and provide good medicine for the prevention, treatment and rehabilitation of new corona virus infection. Hand in hand, human being would be free of coronavirus fears. Harmless, Coroless! 


\section{AUTHOR CONTRIBUTIONS}

Dr. Nie Leng discovered the use of Kyllinga brevifolia Rottb and Coroless for Covid-19 prevention and treatment. Liang Youdong participated in the drug efficacy analysis. Yang Xinwei had clinical advice.

\section{ACKNOWLEDGMENTS}

This research was funded by Suzhou Science and Technology Bureau's 2020 Coronavirus Infection Emergency Prevention and Control Technology Special Project (XG32) and Shenzhen Longhua District Science and Technology Innovation Special Fund (2019 Innovation Competition Award).

\section{REFERENCES}

1. Huang Chaolin, Huang Lixue, Wang Yeming,etc. 6-month consequces of COVID-19 in patients discharged from hospital: a cohort study. The Lancet, 2021, 397:220-232.

2. Nie Leng, Liang Youdong, Yang Xinwei, Huang Xiaohao, Wang Shumei, Chen Jianfei, Analysis of Kyllinga brevifolia Rottb for the prevention and treatment of Covid-19 and the rehabilitation of kidney, liver and cardiovascular diseases, Medicinal Plant, accepted.

3. Nie Leng, Liang Youdong. The application of Kyllinga brevifolia Rottb in the prevention and treatment of Covid-19, Patent number 20201135852, Patent number 202110106608.2, China.

4. National Compilation and Compilation Team of Chinese Herbal Medicine. National Compilation of Chinese Herbal Medicine (Volume One). Beijing: People's Medical Publisher, 1975:191.

5. https://news.tsinghua.edu.cn/info/1003/84825.htm?ivk_sa=1023197a

6. Alina Renz, Lina Widerspick1 and Andreas Drager, FBA reveals guanylate kinase as a potential target for antiviral therapies against SARSCoV-2, Bioinformatics, 36(26), 2020, i813-i821 
Figure 2 Cells after co-incubation with Coroless for $72 \mathrm{~h}$

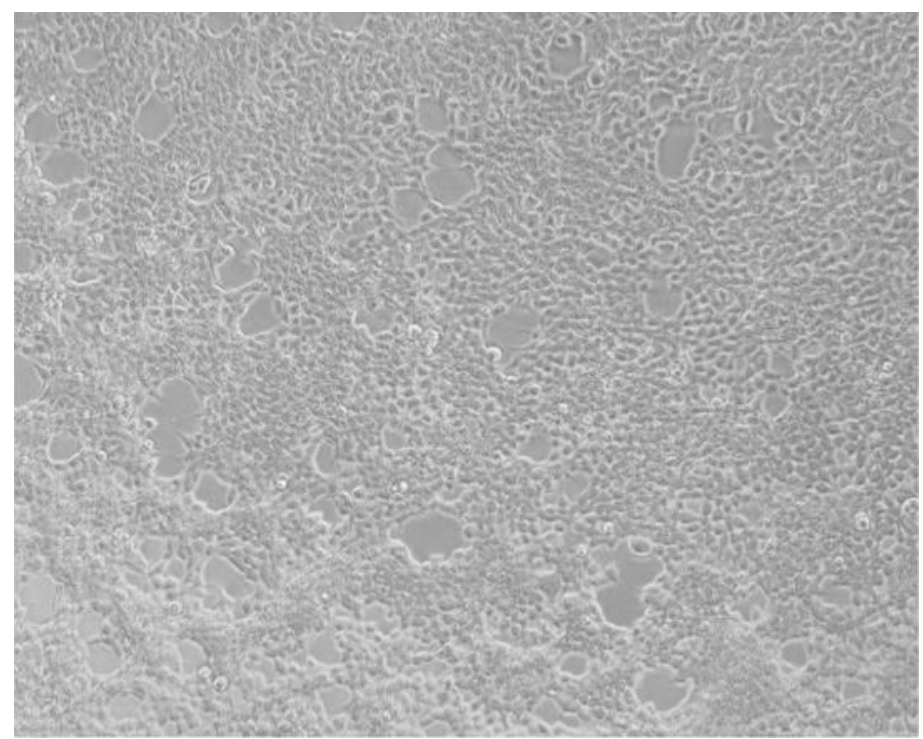


Table 1 Covid-19 Pseudo-virus Cell Infection Experiment with Coroless

\begin{tabular}{|c|c|c|c|c|}
\hline $\begin{array}{c}\text { Samples in serial } \\
\text { dilutions }\end{array}$ & RLU1 & RLU2 & AVE & $\begin{array}{c}\text { inhibition } \\
\text { rate } \%\end{array}$ \\
\hline 1 & 3971 & 12903 & $8.44 \mathrm{E}+03$ & 98.89 \\
\hline 2 & 439972 & 236293 & $3.38 \mathrm{E}+05$ & 54.37 \\
\hline 4 & 182580 & 279481 & $2.31 \mathrm{E}+05$ & 68.84 \\
\hline 8 & 211921 & 307354 & $2.60 \mathrm{E}+05$ & 64.97 \\
\hline 16 & 245116 & 363015 & $3.04 \mathrm{E}+05$ & 58.97 \\
\hline 32 & 277001 & 272255 & $2.75 \mathrm{E}+05$ & 62.95 \\
\hline 64 & 219713 & 491851 & $3.56 \mathrm{E}+05$ & 51.95 \\
\hline 128 & 198948 & 104996 & $1.52 \mathrm{E}+05$ & 79.51 \\
\hline negative control & 205 & 286 & $2.46 \mathrm{E}+02$ & - \\
\hline positive control & 939502 & 542045 & $7.41 \mathrm{E}+05$ & - \\
\hline
\end{tabular}

Table 2 Covid-19 Pseudo-virus cell infection Experiment

\begin{tabular}{|c|c|c|c|c|}
\hline Sample & RLU1 & RLU2 & AVE & $\begin{array}{c}\text { inhibition } \\
\text { rate } / \%\end{array}$ \\
\hline Coroless & 3971 & 12903 & $8.44 \mathrm{E}+03$ & 98.89 \\
\hline Kyllinga & 90116 & 92323 & $9.12 \mathrm{E}+04$ & 87.71 \\
\hline
\end{tabular}


Table 3 Coroless's effect on ACE2: RBD binding competition inhibition experiment

\begin{tabular}{|c|c|c|c|c|}
\hline 2nd Ab & \multicolumn{4}{|c|}{ SinoA5327-his Scale up/HRP } \\
\hline Coating: & \multicolumn{3}{|c|}{ 2019-nCoV-RBD } \\
\hline Sampling2 & \multicolumn{3}{|c|}{ ACE2-His(Cat:10108-H08B;Lot:MA14MA1401)- 1: 40 } \\
\hline \multirow{2}{*}{ Sampling: 6-1 } & OD450-1 & OD450-2 & AVRAGE & percent activity \\
\hline \multirow{2}{*}{ Blank } & 0.821 & 0.797 & 0.81 & 100.500 \\
\hline 0.000051 & 0.815 & 0.793 & 0.80 & 104.938 \\
\hline 0.000152 & 0.843 & 0.836 & 0.84 & 99.750 \\
\hline \multirow{2}{*}{0.000457} & 0.761 & 0.835 & 0.80 & 100.188 \\
\hline 0.001372 & 0.746 & 0.857 & 0.80 & 97.188 \\
\hline 0.004115 & 0.743 & 0.812 & 0.78 & 97.000 \\
\hline 0.012346 & 0.73 & 0.822 & 0.78 & 103.313 \\
\hline \multirow{2}{*}{0.037037} & 0.779 & 0.874 & 0.83 & 99.938 \\
\cline { 2 - 5 } 0.111111 & 0.75 & 0.849 & 0.80 & 98.313 \\
\hline 0.333 & 0.777 & 0.796 & 0.79 & 89.750 \\
\hline 1 & 0.685 & 0.751 & 0.72 & \\
\hline
\end{tabular}

Table4 Kyllinga's effect on ACE2: RBD binding competition inhibition experiment

\begin{tabular}{|c|c|c|c|c|}
\hline 2nd Ab & \multicolumn{4}{|c|}{ SinoA5327-his Scale up/HRP } \\
\hline Coating: & \multicolumn{4}{|c|}{ 2019-nCoV-RBD } \\
\hline Sampling2 & \multicolumn{4}{|c|}{ ACE2-His(Cat:10108-H08B;Lot:MA14MA1401)- 1: 40} \\
\hline Sampling: $5-1$ & \multicolumn{4}{|c|}{ SinoA5327-his Scale up/HRP } \\
\hline Blank & 0.811 & 0.782 & 0.797 & \\
\hline 0.000051 & 0.872 & 0.745 & 0.809 & 101.443 \\
\hline 0.000152 & 0.864 & 0.744 & 0.804 & 100.878 \\
\hline 0.000457 & 0.737 & 0.686 & 0.712 & 89.272 \\
\hline 0.001372 & 0.766 & 0.726 & 0.746 & 93.601 \\
\hline 0.004115 & 0.74 & 0.782 & 0.761 & 95.483 \\
\hline 0.012346 & 0.738 & 0.729 & 0.734 & 92.033 \\
\hline 0.037037 & 0.721 & 0.719 & 0.720 & 90.339 \\
\hline 0.111111 & 0.616 & 0.607 & 0.612 & 76.725 \\
\hline 0.333 & 0.435 & 0.432 & 0.434 & 54.391 \\
\hline 1 & 0.249 & 0.288 & 0.269 & 33.689 \\
\hline
\end{tabular}


Figure 3 Competitive inhibition curve of Kyllinga on ACE2:RBD binding

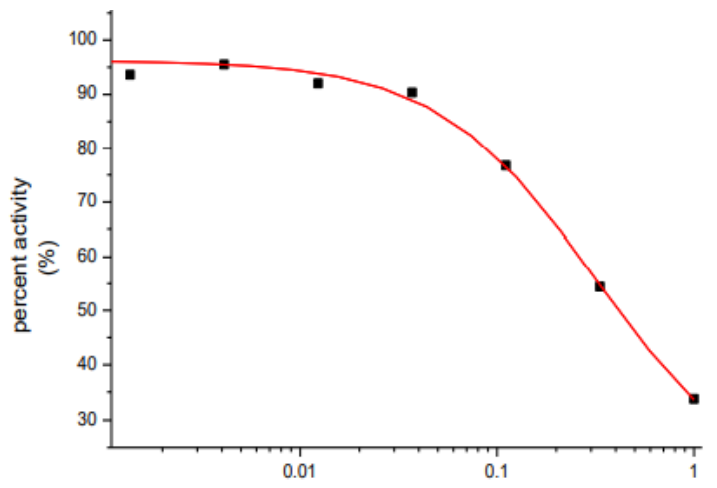

